\title{
A WIDE SPEED RANGE SENSORLESS CONTROL TECHNIQUE OF BRUSHLESS DC MOTORS FOR ELECTRIC PROPULSORS
}

Min-Fu Hsieh

Department of Systems and Naval Mechatronic Engineering, National Cheng Kung University, No. 1, University Road, Tainan 701, Taiwan., mfhsieh@mail.ncku.edu.tw

Hung-Ju Liao

Department of Systems and Naval Mechatronic Engineering, National Cheng Kung University, No. 1, University Road, Tainan 701, Taiwan.

Follow this and additional works at: https://jmstt.ntou.edu.tw/journal

Part of the Transportation Engineering Commons

\section{Recommended Citation}

Hsieh, Min-Fu and Liao, Hung-Ju (2010) "A WIDE SPEED RANGE SENSORLESS CONTROL TECHNIQUE OF BRUSHLESS DC MOTORS FOR ELECTRIC PROPULSORS," Journal of Marine Science and Technology. Vol. 18: Iss. 5, Article 15. DOI: $10.51400 / 2709-6998.1927$

Available at: https://jmstt.ntou.edu.tw/journal/vol18/iss5/15

This Research Article is brought to you for free and open access by Journal of Marine Science and Technology. It has been accepted for inclusion in Journal of Marine Science and Technology by an authorized editor of Journal of Marine Science and Technology. 


\section{A WIDE SPEED RANGE SENSORLESS CONTROL TECHNIQUE OF BRUSHLESS DC}

MOTORS FOR ELECTRIC PROPULSORS

\section{Acknowledgements}

This research work was supported by the National Science Council, Taiwan ROC, under contract 95-2221-E-006-471 and 96-2622-E-006-029-CC3. The authors would like to thank Joseph Tech Co. for their help in experiments. Dr. Cheng-Hu Chen is also acknowledged for his advice during the research period. 


\title{
A WIDE SPEED RANGE SENSORLESS CONTROL TECHNIQUE OF BRUSHLESS DC MOTORS FOR ELECTRIC PROPULSORS
}

\author{
Min-Fu Hsieh* and Hung-Ju Liao*
}

Key words: permanent-magnet brushless DC motor, sensorless, electric propulsor, thruster.

\begin{abstract}
This paper presents a sensorless drive technique for permanent-magnet brushless DC motors applied to electric propulsors of small ships or underwater vehicles. Propulsors enveloping electric motors (e.g., POD or subsea thrusters) have been increasingly applied due to their advantages of excellent maneuverability, high efficiency and low maintenance costs. To secure reliable operation under water, sensorless control is considered as an appropriate technique. However, conventional sensorless techniques often suffer problems of narrow speed range and low efficiency, particularly when the propulsors sustain heavy load at high speed operation. Hence, a sensorless technique with a wide speed range is developed in this paper using an enhanced commutation method. A brushless DC motor is first used to demonstrate the effectiveness of the developed technique. An electric thruster is further tested, where the results show that the efficiency matches that of the common Hall element commutation approach.
\end{abstract}

\section{INTRODUCTION}

Electronically controlled motors are widely used in various applications demanding speed regulation and control. Permanent-magnet (PM) brushless DC (BLDC) motors are a typical example with advantages of high efficiency, high power density and maintenance-free operation $[10,11]$. However, in some applications with limited space, high environmental temperature or severe vibrations, use of Hall-effect sensors for rotor position detection may encounter potential hazards or problems $[4,5]$. For example, high temperature can affect the characteristics or cause failure to sensors while insufficient space would not be able to accommodate sensors. Other conditions such as severe vibration or in-water operation may

Paper submitted 04/07/09; revised 09/22/09; accepted 10/16/09. Author for correspondence: Min-Fu Hsieh (e-mail: mfhsieh@mail.ncku.edu.tw).

*Department of Systems and Naval Mechatronic Engineering, National Cheng Kung University, No. 1, University Road, Tainan 701, Taiwan. involve a risk of sensor destruction. Therefore, sensorless control is considered as an appropriate technique for such applications.

Due to the demand of environmental protection and the increasing energy crisis, electric motors have been recognized as a suitable device for propulsions of vehicles or ships [1]. However, in these applications, the operating environment is harsh due to severe humidity, vibration, or high temperature. This leads to a serious challenge to the reliability of commutation for BLDC motors $[1,4,5]$. In the case of underwater vehicles, sensorless control can reduce not only the number of external wiring/connections between the motor and driver but also the maintenance requirement caused by vibration $[1,18]$. A typical remotely operated vehicle is equipped with four to six thrusters and a significant amount of cables and connectors can be reduced with sensorless control. This will improve the system reliability and reduce cost. Some thrusters for under water vehicles are designed to allow water to flow inside the motors, such that it is not appropriate for Hall-effect sensors to be installed [9]. This accounts for the necessity of sensorless control.

There are studies reporting sensorless control techniques for BLDC motors [1, 3-7, 12-19]. Some of them are based on detection of zero crossing points (ZCPs) of back electromotive force (EMF) or terminal voltages $[6,12,13,16]$. The $\mathrm{ZCP}$ techniques often require the voltage of the neutral point or virtual neutral point, which are used to compare with terminal voltages for commutation. Iizuka et al. [12] proposed a sensorless approach that compares filtered terminal voltages with that of virtual neutral points for commutation. In this case, a phase shift to the ZCPs is required for correct commutation. Chen and Liaw [6] compared terminal voltages with virtual neutral points to obtain the three phase voltages and thus the line-to-line voltages, whose ZCPs are used as the commutation points. However, neutral or virtual neutral points often contain high-frequency noise [16] and windings of common motors may have no lead-outs for neutral points. To avoid this problem, Damodharan and Vasudevan [7] indirectly obtained back-EMF ZCPs with a series of signal subtractions and manipulation. However, a thirty electric degree phase shift is still required for correct commutation, and the entire circuitry is complex. Chen and Cheng [3-5] directly compared the fil- 
tered average terminal voltages to obtain the required signals for commutation. For the above methods, the inclusion of lowpass filters (LPFs) may solve the noise problem due to pulsewidth modulation (PWM) switching but will limit the speed range (because of the phase lag that affects the commutation accuracy). In addition, little literature discussed the speed range that can be achieved under heavy load conditions.

In this paper, a sensorless control technique is developed based on terminal voltage comparison for commutation of BLDC motors applied to electric propulsors. From an electric motor point of view, the typical load characteristics of a propeller can be illustrated with the curves shown in Fig. 1. It can be seen that the torque is approximately proportional to the propeller rotational speed. As the inlet water velocity to the propeller or the vehicle speed increases, the torque required for the same rotational speed decreases [8]. This indicates that the torque for low speed operation is very low, which is considered as an advantage for sensorless control because its startup is often a problem to conquer. On the other hand, the dramatically increasing torque for high speed reveals a severe challenge to sensorless technique due to its poor performance and efficiency at high torque and high current. This will limit the speed range. Therefore, this paper aims to improve the sensorless performance and efficiency of propulsors under heavy load for high speed operation, as well as to solve the problem at low speed and start-up due to weak signals. Thus, the speed range can be improved for application of sensorless control to electric propulsors.

The remainder of this paper is organized as follows. Section II will analyze the commutation approach for sensorless control, and Section III describes the detail of the proposed technique. The system architecture is illustrated in Section IV while the experimental results for both off-water and in-water tests that verify the proposed method are presented in Section V. Finally, a conclusion is given in Section VI.

\section{ANALYSIS OF COMMUTATION}

The equivalent circuit for a three-phase BLDC motor with its power stage is shown in Fig. 2, where $V_{d c}$ is the DC bus voltage, $G_{1 H} / G_{2 H} / G_{3 H} / G_{1 L} / G_{2 L} / G_{3 L}$ are the MOSFETs forming the power stage, $n$ is the neutral point for the wye connection, $R_{a} / R_{b} / R_{c}$ and $L_{a} / L_{b} / L_{c}$ are the motor phase resistances and inductances, respectively, $e_{a} / e_{b} / e_{c}$ are the back EMFs and $i_{a} / i_{b} / i_{c}$ are the phase currents. Ideally, the zero crossings of back EMFs are the most suitable signals for commutation because they have a firm relationship with rotor position. However, the circuits to acquire the back EMFs are often complex. Also, the ZCPs of back EMFs require a $30^{\circ} \mathrm{E}$ phase shifter, which also adds complexity to the circuits. Therefore, use of the easily-acquired terminal voltages is considered as a better solution $[3,5]$. To develop the proposed technique analysis for conventional sensorless approaches first analyzed as follows.

As shown in Fig. 2, assuming the resistances of the three phases are identical, and the rotor inductances do not vary with

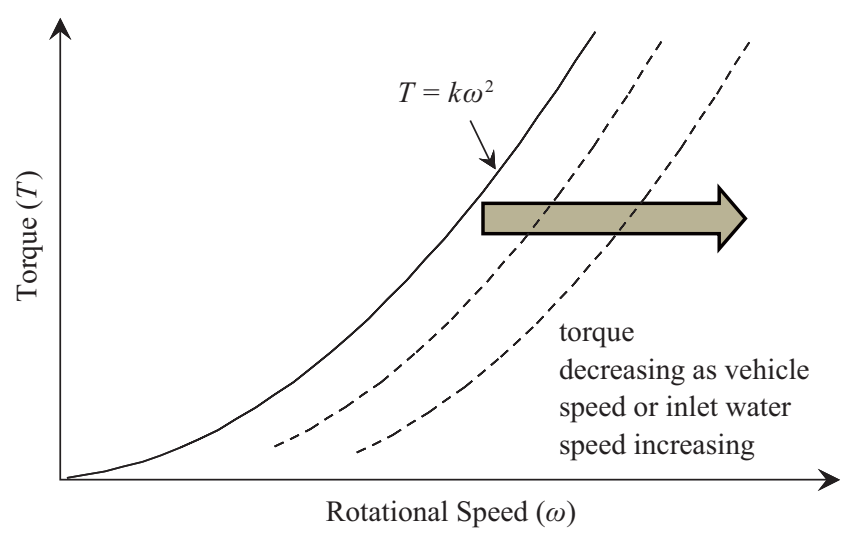

Fig. 1. Load characteristic of propeller in the viewpoint of electric motors.

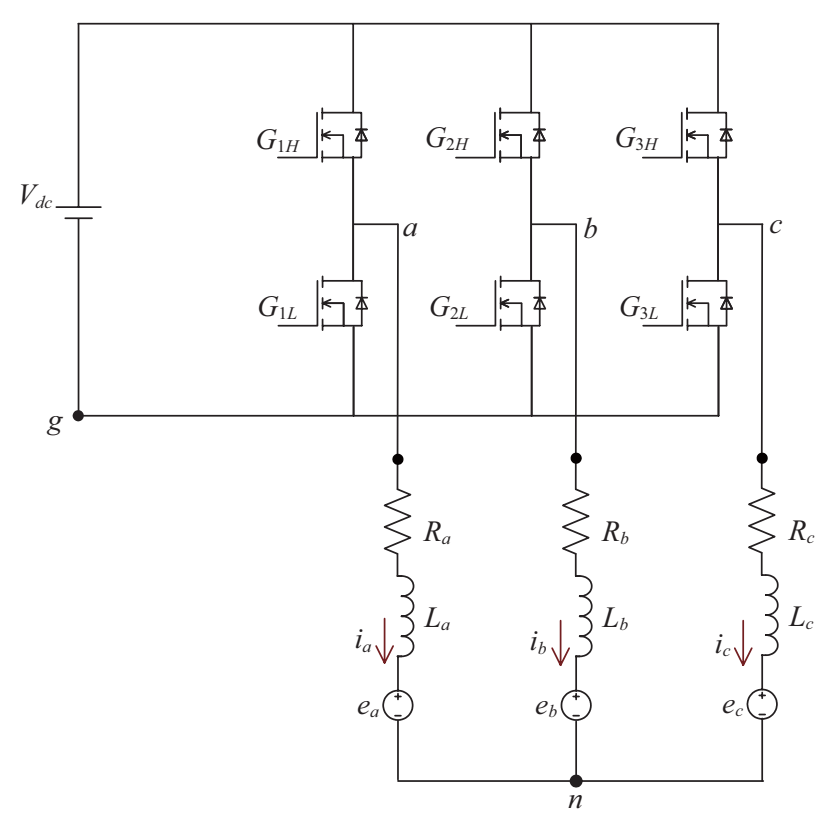

Fig. 2. Equivalent circuit of BLDC motor with power stage.

position, thus $R_{a}=R_{b}=R_{c}=R, L_{a}=L_{b}=L_{c}=L_{s}$, and the mutual inductances, denoted $L_{M}$, are the same. The terminal voltages of the three phases can then be given as:

$$
\begin{aligned}
& V_{a g}=R i_{a}+L \frac{d}{d t} i_{a}+e_{a}+V_{n g} \\
& V_{b g}=R i_{b}+L \frac{d}{d t} i_{b}+e_{b}+V_{n g} \\
& V_{c g}=R i_{c}+L \frac{d}{d t} i_{c}+e_{c}+V_{n g}
\end{aligned}
$$

where $L=L_{s}-L_{M}$ and $V_{n g}$ is the voltage of the neutral point referring to the ground. Thus, the line-to-line voltages, $V_{a c}$, $V_{b a}, V_{c b}$, can be expressed as: 


$$
\begin{aligned}
& V_{a b}=R\left(i_{a}-i_{b}\right)+L \frac{d}{d t}\left(i_{a}-i_{b}\right)+\left(e_{a}-e_{b}\right) \\
& V_{b c}=R\left(i_{b}-i_{c}\right)+L \frac{d}{d t}\left(i_{b}-i_{c}\right)+\left(e_{b}-e_{c}\right) \\
& V_{c a}=R\left(i_{c}-i_{a}\right)+L \frac{d}{d t}\left(i_{c}-i_{a}\right)+\left(e_{c}-e_{a}\right)
\end{aligned}
$$

Equations (4)-(6) describe the relationship of the line-toline voltages and the back EMFs. For common BLDC drives (i.e., the six-step commutation), the phase currents are assumed to be constant in an excitation step at steady state so that the phase difference and inductor voltages can be neglected. In PM motors, the excitation will be applied in phase with the back EMF waveforms to produce maximum and constant torque. Since back EMFs correspond with the rotor positions, it implies that, according to (4)-(6), the relationships of the line-toline voltages to the rotor positions can also be identified.

Figure 3 shows the ideal voltages and signals for the BLDC motors running in a certain direction, including terminal voltage, phase voltages, phase currents, sample line-to-line voltages with their subtractions, and Hall sensor signals, etc. As can be seen, finding the ZCPs of the line-to-line voltages can determine the commutation signals without the voltages of the neutral or virtual neutral points. For instance, the ZCP of $V_{a b}$ can determine the estimated commutation signal $H_{E 2}\left(V_{c c}\right.$ in Fig. 3 is the operating voltage of Hall ICs). This is one possible approach for sensorless control although LPFs are needed for the terminal voltages prior to calculation of the line-to-line voltages. Thus, commutation accuracy can be affected by the possible phase lag. Also, subtractors and zero detection circuits are further required for acquiring estimated commutation signals. Alternatively, indirect back EMFs can be determined by subtractions of the line-to-line voltages in (4)-(6), and this will give [7]:

$$
\begin{aligned}
& V_{b c}-V_{c a}=-2 e_{c} \\
& V_{a b}-V_{b c}=-2 e_{b} \\
& V_{c a}-V_{a b}=-2 e_{a}
\end{aligned}
$$

where for any steps in Fig. 3, the voltages on the resistors of the two excited phases will cancel each other so as the two inductors (e.g., in the zone of $\theta_{e}=120^{\circ} \mathrm{E}$ to $180^{\circ} \mathrm{E}$ in Fig. 3, $i_{a}=-i_{c}$ and $i_{b}=0$, such that the subtraction of $V_{a b}$ in (4) and $V_{b c}$ in (5) makes $-2 e_{b}$ in (8)). This can indirectly acquire the back EMFs but a complicated process and complex circuitry is needed. A phase shift is also necessary for correct commutation, as shown in Fig. 3. Moreover, the line-to-line voltage lags the phase voltages $\left(V_{a n}, V_{b n}\right.$ and $\left.V_{c n}\right)$ by $30^{\circ} \mathrm{E}$ (e.g., $V_{a b}$ lags $V_{a n}$ ) and for the approaches using phase voltages for commutation [12], a phase shift is again required.

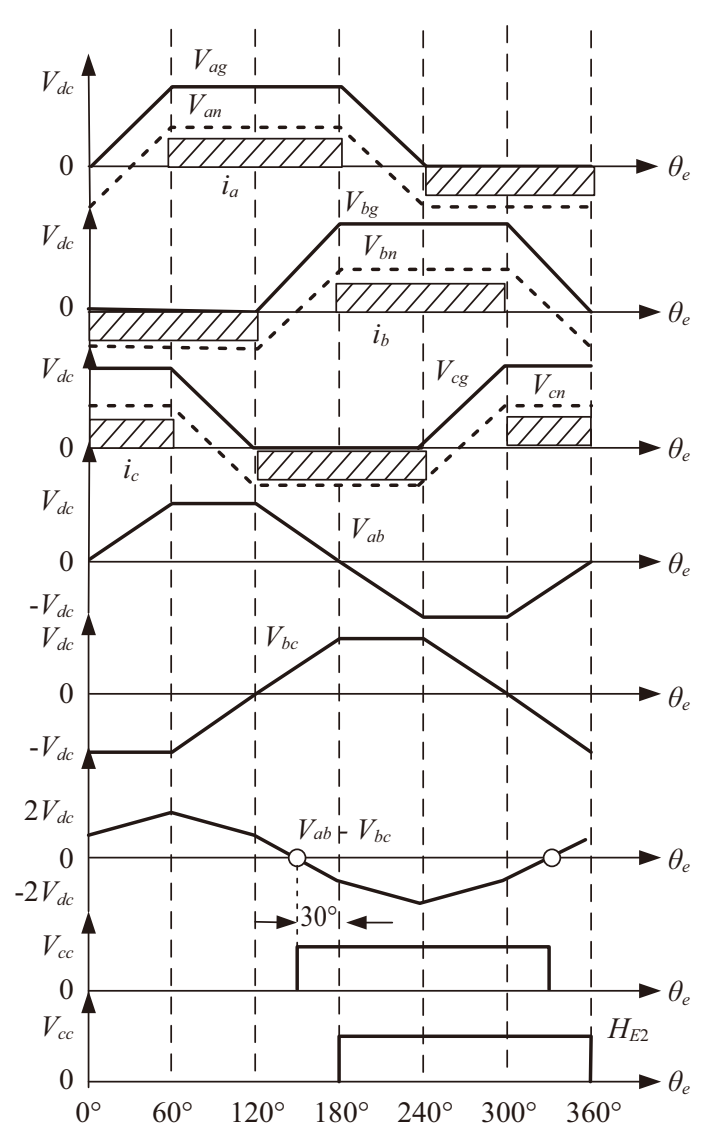

Fig. 3. Various ideal voltages and signals in BLDC motor $\left(\theta_{e}\right.$ is electrical angle, and the definition is applied to the entire paper).

By observing the terminal voltages/Hall signals in Fig. 3, an alternative solution can be discovered. At $180^{\circ} \mathrm{E}$ where the comparison between the terminal voltages of phases $A$ and $B$ is made, i.e., $V_{b g} \geq V_{a g}$ (neglecting the PWM effect), the estimated commutation signal $H_{E 2}$ becomes high and this indicates a commutation point. This also applies to the other two cases: comparison between phases $B$ and $C$, and that between phases $C$ and $A$. Therefore, the circuit shown in Fig. 4 can be used to generate commutation signals (modified from [4]). As can be seen, the circuit consists of a LPF (with a voltage divider) for each phase and three comparators. The LPFs are used to reject the noise on the average terminal voltages caused by PWM switching if the duty is less than $100 \%$. The three filtered average terminal voltages $A_{a v g}, B_{a v g}, C_{a v g}$ are compared pair by pair to generate the required estimated commutation signals that can be used to replace the Hall signals, as indicated in Fig. 5. These signals, denoted $H_{E 1}, H_{E 2}$ and $H_{E 3}$, are hereafter called "estimated commutation signals" to distinguish from the actual Hall signals. This approach takes advantage of using only comparators to compare the terminal voltages, and the commutation signals can be obtained.

Although this approach has been investigated in $[4,5]$, the effect of the LPFs and the speed range limitation has not been discussed. These problems are critical to propulsion applica- 


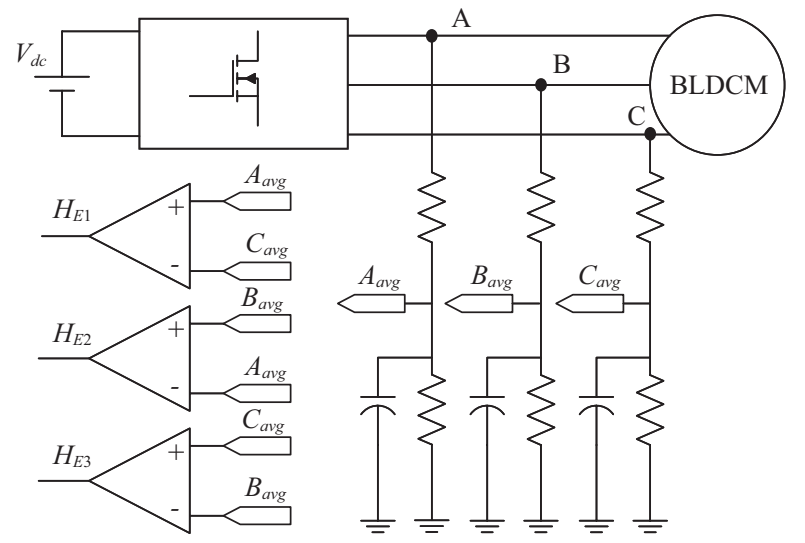

Fig. 4. Circuit of commutation signal generation (modified from [4]).

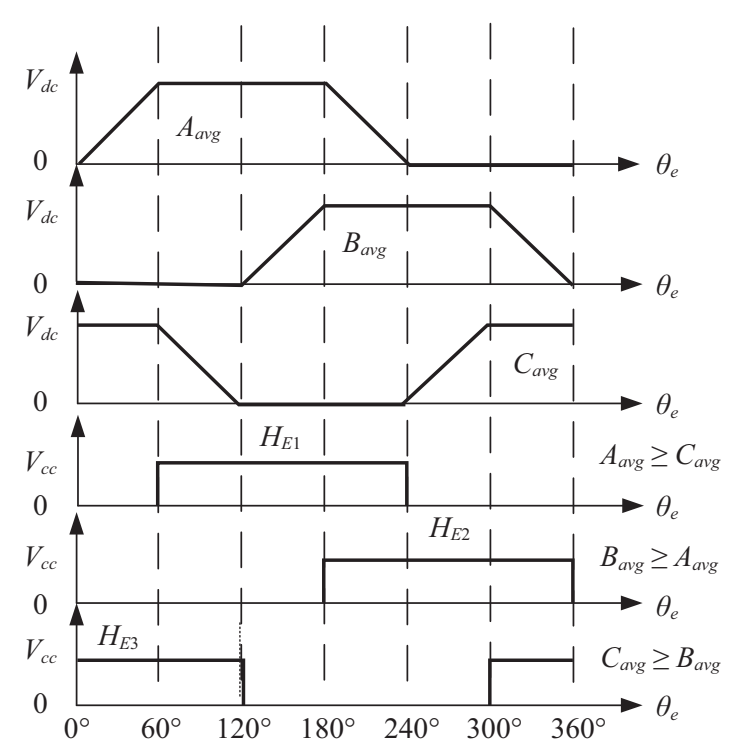

Fig. 5. Commutation signals generated by terminal voltage comparison.

tions or the likes. As shown in Fig. 4, the LPFs are used to reject the effect of high-frequency PWM switching. However, the LPFs will cause a phase lag to the terminal voltages, and this subsequently affects the commutation accuracy, efficiency and speed range. To avoid the phase lag, the LPFs should be designed to possess a high cut-off frequency. Although this minimizes the phase delay at motor high speed, there are some drawbacks. For instance, the signal-to-noise ratio would be very poor at low speed operation due to the high cut-off frequency. The noise will result in commutation error, which will significantly reduce the motor low speed performance and worsen the start-up problem. In contrast, using LPFs with a low cut-off frequency will severely cause the phase lag at high speed and limit the speed range. This indicates that the indispensable LPFs have a negative effect that limits the speed range. Therefore, this paper proposes a regulable cut-off frequency which satisfies the requirement for both low speed and high speed operations.

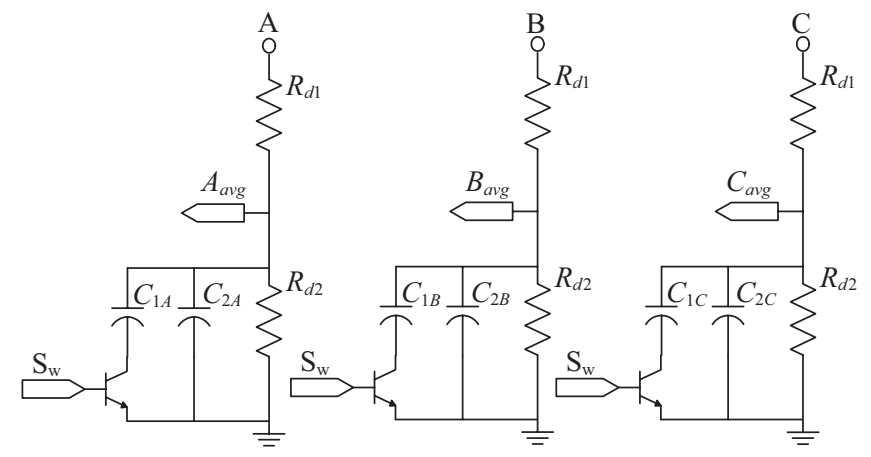

Fig. 6. Low-pass filters with regulable cut-off frequencies.

It is noted that the BLDC is initially driven as a synchronous motor because at the start-up, the magnitude of the estimated signals is zero or inadequate for commutation. To enable the commutation using the estimated signals, the motor should achieve a certain speed level. Moreover, at the start-up, the noise added to the already-weak signals will cause problems for switching to the commutation mode. Thus, a higher threshold speed is needed for the motor being switched to the commutation mode, and consequently the motor performance decreases. The proposed approach is capable of applying commutation at low speed by the regulable cut-off frequency.

\section{FILTER DESIGN FOR COMMUTATION}

The proposed cut-off frequency is illustrated in this section. As shown in Fig. 6, each filter has two capacitors, one of which is connected to a transistor controlled by a microcontroller. The microcontroller changes the cut-off frequency according to the motor speed. This configuration provides two cut-off frequencies in each filter so that a wide range of noise rejection can be achieved, and the phase lag can be reduced. The LPF with a lower cut-off frequency is used for the low terminal voltage at low speed to reject all sorts of noise. This improves the signal quality and makes it easy for start-up. When the motor speed reaches a threshold, the LPF is switched to a higher cut-off frequency by disconnecting one of the capacitors to reduce the phase lag and expand the speed range. This implies that, at low speed operation, a low cut-off frequency is needed while at high speed a high cut-off frequency is required. The two cut-off frequencies should be carefully designed.

In Fig. 6, the capacitors $C_{1 A}, C_{1 B}$ and $C_{1 C}$ are controlled to change the cut-off frequencies to fit different speed range. At low speed, the three capacitors are connected for the larger capacitance and lower cut-off frequency, which is denoted $f_{\text {cut_ } 1}$. As mentioned, the BLDC motor is initially driven as a synchronous motor from standstill until the estimated commutation signals from the comparators can be used for commutation. The period of the synchronous motor mode should ideally be as short as possible to improve the motor starting performance and controllability. At the threshold speed of switching from the synchronous model to the commutation mode, the 


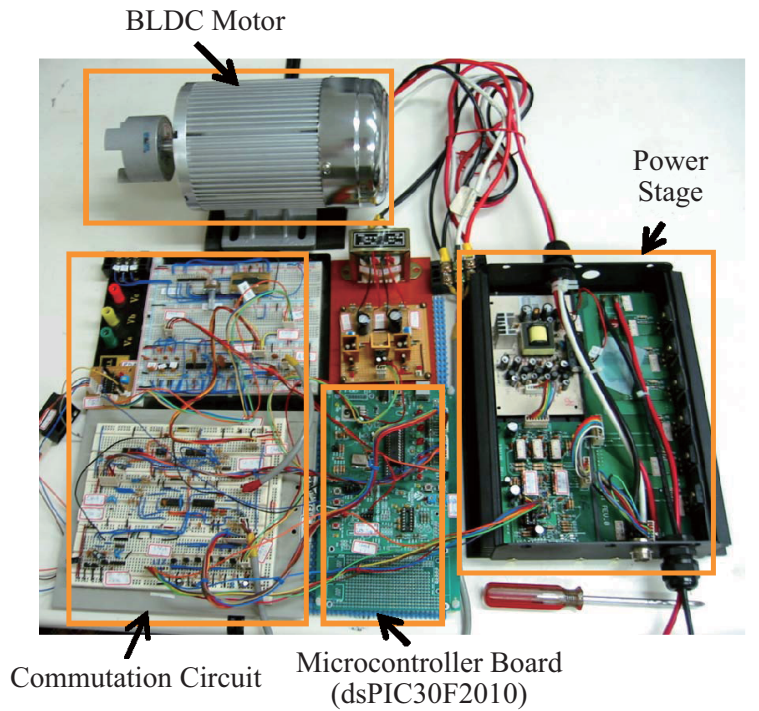

Fig. 7. Investigated BLDC motor and developed sensorless circuitry.

Table 1. Motor specifications.

\begin{tabular}{|c|c|}
\hline rotor poles & 8 \\
\hline rated output power & $750(\mathrm{~W})$ \\
\hline no load speed & $1650(\mathrm{rpm})$ \\
\hline rated voltage & $36(\mathrm{~V})$ \\
\hline rated speed & $1200(\mathrm{rpm})$ \\
\hline rated torque & $6(\mathrm{~N}-\mathrm{m})$ \\
\hline
\end{tabular}

mode-switching frequency, $f_{e_{-} \text {start }}$ should be lower than but close to $f_{\text {cut } 1 \text { it }}$ to ensure good signal quality. At high speed, the three capacitors $C_{1 A}, C_{1 B}, C_{1 C}$ are disconnected for a higher

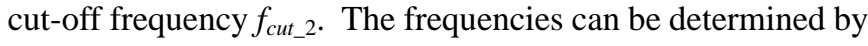
the following equations:

$$
\begin{gathered}
f_{\text {cut }-1}=\frac{1}{2 \pi R_{m}\left(C_{1 X}+C_{2 X}\right)} \\
f_{\text {cut }-2}=\frac{1}{2 \pi R_{m} C_{2 X}}
\end{gathered}
$$

where the " $x$ " in $C_{1 X}$ and $C_{2 X}$ represents $A, B$ or $C$, and $R_{m}=$ $R_{d 1} R_{d 2} /\left(R_{d 1}+R_{d 2}\right)$. The relationship for all the related frequencies can be given as follows:

$$
f_{e_{-} \text {start }}<f_{\text {cut } \_1}<f_{e_{-} r u n}<f_{\text {cut }-2}<f_{\text {pwm }}
$$

where $f_{p w m}$ represents the switching frequency of the PWM, and $f_{e_{\text {run }}}$ is the highest operation frequencies when the motor runs at the no load speed in the BLDC commutation mode. The cut-off frequency $f_{\text {cut } 2}$, which is significantly higher than the motor highest frequency (at no load speed), is responsible for rejecting PWM noise without causing severe phase lag.

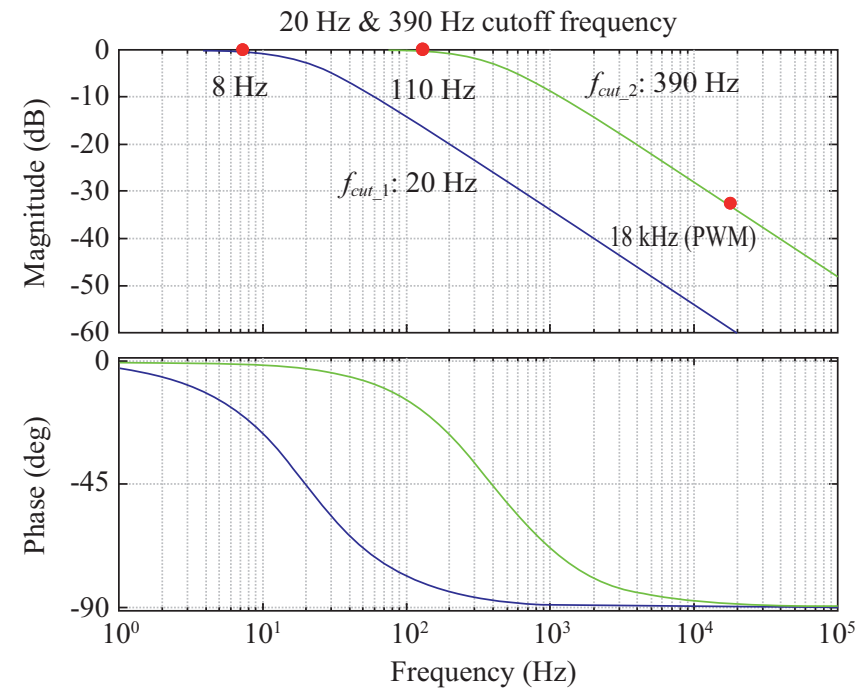

Fig. 8. Bode plot for design of regulable filters.

For the investigated motor (Fig. 7) with the specifications shown in Table 1, the no-load speed is $1650 \mathrm{rpm}$ and thus the frequency $f_{e_{-} r u n}$ is $110 \mathrm{~Hz}$ for an 8 pole configuration. As the Bode plot for the two filters shown in Fig. 8 , the $20 \mathrm{~Hz} f_{\text {cut } \_1}$ rejects noises for the terminal voltages at $8 \mathrm{~Hz} f_{e_{-} \text {start }}$. The 390 $\mathrm{Hz} f_{\text {cut_2 }}$ allows the motor runs at the no load speed $(110 \mathrm{~Hz})$, by rejecting the $18 \mathrm{kHz} f_{p w m}$ and causing little phase lag. The speed range of the motors is expected to be effectively improved with this design.

\section{SYSTEM ARCHITECTURE}

To implement the proposed sensorless technique, a 16-bit microcontroller, dsPIC, produce by Microchip is used to work with the developed circuit (Figs. 6 and 7) and the MOSFETequipped power stage to produce the estimated commutation signals and drive the BLDC motor. The microcontroller is programmed to deal with the start-up process, commutation, cut-off frequency regulation, etc. For accurate commutation, a function called "digital compensation" is also included, which is used to compensate any phase offset caused to the estimated signals due to various speed or load conditions. Also, another technique called "phase advance control" is applied in the developed algorithm to further extend the speed range. These will be detailed in the following.

\section{Start-up Process}

The entire sensorless system is shown in Fig. 9. The direction of rotation is first determined by the command given to the sensorless drive for speed control. The direction of rotation indicates a corresponding excitation sequence for the synchronous motor mode in the start-up process. Following this, the start-up process is activated until the motor switches to the commutation mode ("closed-loop commutation" in Fig. 9). During the start-up, the synchronous frequency 


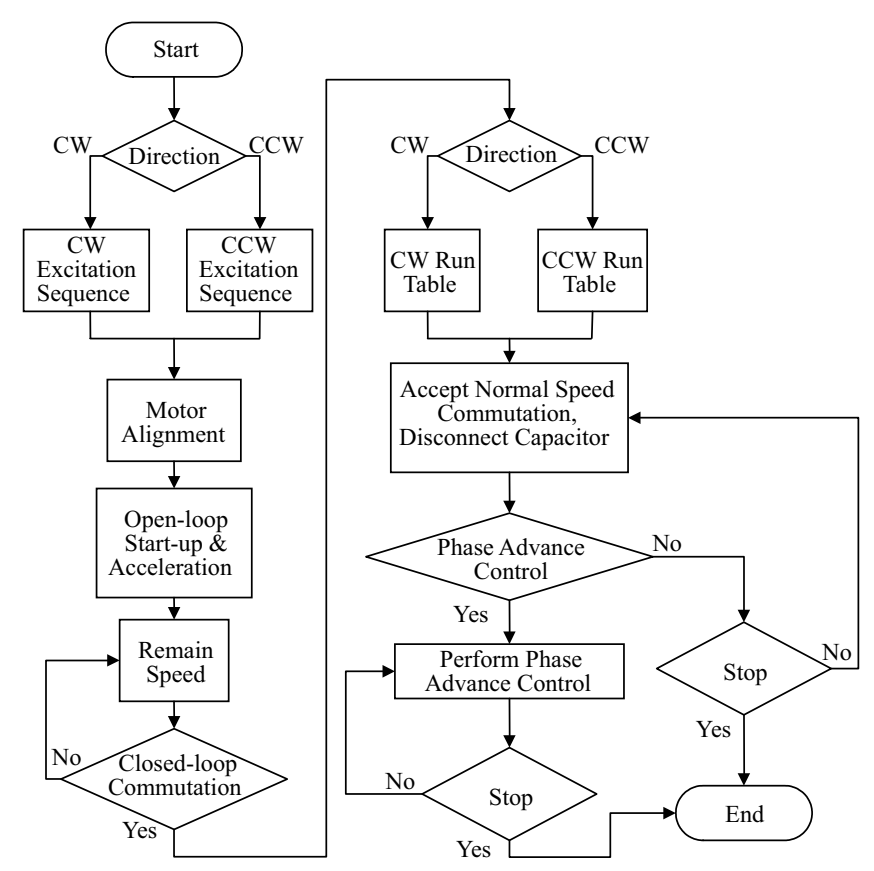

Fig. 9. Proposed entire sensorless control process.

will gradually increase until the threshold frequency $f_{e_{-} \text {start }}$ is reached. At $f_{e_{-} \text {start }}$, the commutation signal estimated by the developed circuit should have sufficient magnitude and quality for mode switching. The microcontroller then switches the drive system into the commutation mode using the estimated signals generated by the circuits (Fig. 7). In addition to signal magnitude and quality, the mode-switching frequency $f_{e_{-} \text {start }}$ also depends on the load condition, i.e., the load torque at low speed. In this study, the thruster endures a light load at low speed, as shown in Fig. 1, and thereby the mode-switching frequency is determined.

\section{Phase Compensation and Phase Advance Control}

\section{1) Digital Phase Compensation}

Although there are two cut-off frequencies used in the proposed method for wide speed range, the phase lag due to the LPFs is inevitable. In this paper, the phase lag is compensated by digital compensation. Conventional approaches applied constant phase compensation [12], which is not able to compensate in accordance with speed. Some research used look-up table [19] to vary the compensation with speed but a large table should be built if the compensation is to be made precise. Therefore, this paper develops a method that can continuously modify the compensation as speed varies.

As shown in Fig. 10, the commutation signal $H_{E 1}$ is assumed to have a phase lag $\theta_{1}$ due to LPFs. If the motor commutates according to this lagging signal, the motor performance and efficiency will drop. Therefore, for precise commutation, proper compensation should be made. In the developed technique, if there is any phase delay caused to the estimated commutation signal (e.g., $H_{E 1}$ ) by the developed circuits, as

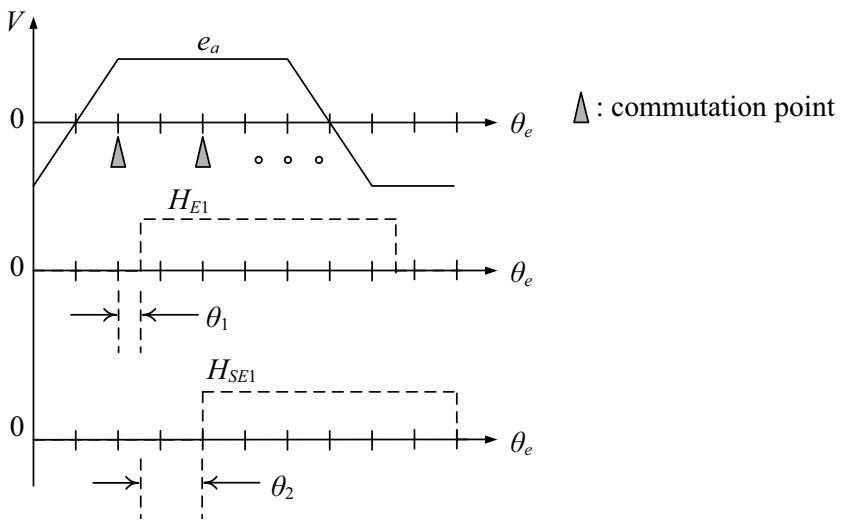

Fig. 10. Phase compensation with respect to back EMF.

shown in Fig. 10, the commutation will not be immediately made to the motor. Instead, the microcontroller will await a delay of $\theta_{2}$ before performing commutation. The $H_{S E 1}$ in Fig. 10 is only a virtual signal dealt with by the control algorithm. To use this virtual signal (with a $60^{\circ} \mathrm{E}$ delay to the original ideal signal) for commutation, indicates that a different commutation table should be applied for correct commutation. It is noted that the sum of $\theta_{1}$ and $\theta_{2}$ is $60^{\circ} \mathrm{E}$, i.e., one of the six steps of commutation in an electric cycle. Institutively, it looks like a $60^{\circ} \mathrm{E}$ delay is caused to commutation, but by applying the new table, the commutation can be made precise.

Ignoring the higher-order harmonics in the trapezoidal terminal voltages, the phase lags caused by the LPF for the startup mode (before switched to commutation mode) can be given as follows by taking Phase A in Fig. 6 as an example:

$$
\theta_{1}=\tan ^{-1}\left(\omega\left(C_{1 A}+C_{2 A}\right) R_{m}\right)
$$

where $\omega$ is the angular velocity of the estimated commutation signals using the proposed commutation circuit ( $\omega$ can also be used to determine the rotor speed of the 8-pole motor), and $R_{m}$ is as defined in (10) and (11). The other symbols can refer to Fig. 6. Similarly, for the commutation mode, where the capacitor $C_{1 A}$ is disconnected, the phase lag becomes

$$
\theta_{1}=\tan ^{-1}\left(\omega C_{2 A} R_{m}\right)
$$

Equations (13) and (14) indicates that a phase lag is expected due to either large capacitance (low speed) or high speed (small capacitance). Consequently, the commutation accuracy is affected, which decreases the motor performance.

As shown in Fig. 10, at a certain motor speed, the compensated angle $\theta_{2}$ is calculated by subtraction of the phase lag $\theta_{1}$ and $60^{\circ} \mathrm{E}$, i.e.,

$$
\theta_{2}=60^{\circ}-\theta_{1}
$$

Thus, the time to compensate can be given by 


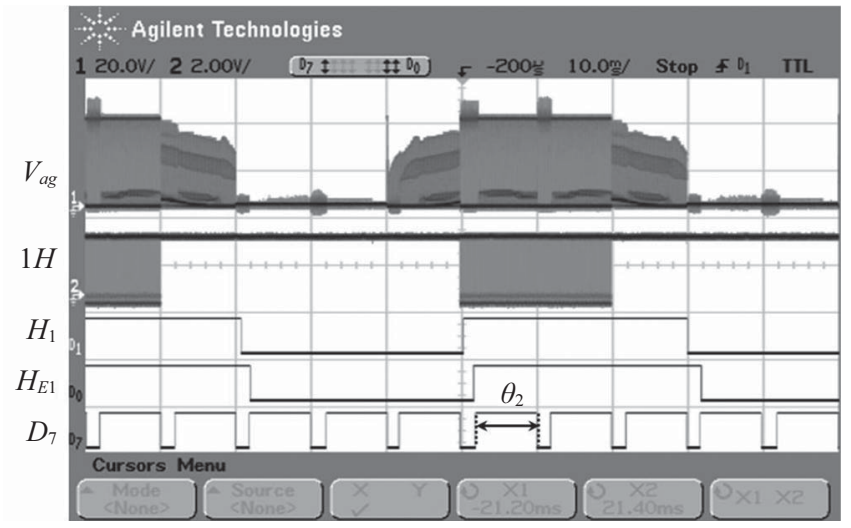

Fig. 11. Signals in sensorless drive: $V_{a g}$ - terminal voltage of phase A, $1 H$ - switch command to the upper arm MOSFETS, $H_{1}$ - actual Hall signal, $H_{E 1}$ - estimated commutation signal and $D_{7}$ - signal for commutation delay ("high" means the angle to delay, i.e., $\theta_{2}$ ). (1: 20 V/div, 2: 2 V/div; D0, D1, D7: Digital; time: $10 \mathrm{~ms} / \mathrm{div})$.

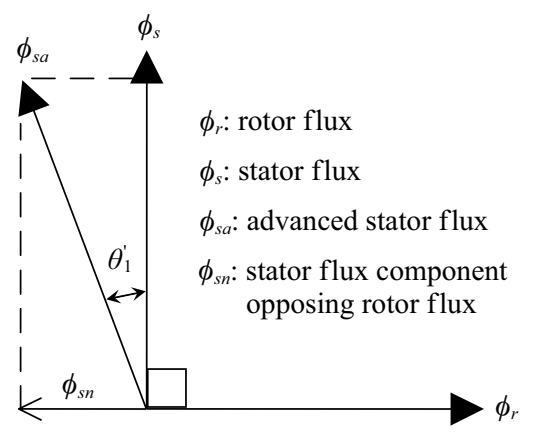

Fig. 12. Phase advance for flux weakening.

$$
t=\theta_{2} / \omega
$$

where $\omega$ is as defined in (13). Equation (16) indicates that the compensation time is determined according to the motor speed. This is included in the control program performed on a microcontroller.

Figure 11 shows the actual signals measured from the BLDC motor at a certain speed using the developed commutation circuit. As can be seen, $\theta_{2}$ is smaller than $60^{\circ} \mathrm{E}$ because the estimated signal $H_{E 1}$ lags the actual Hall signal $H_{1}$. This needs to be compensated. In the following experimental studies, the digital compensation has been applied to all the cases.

\section{2) Phase Advance Control}

In addition to the precise commutation, the digital compensation can also perform phase advance control, which allows the commutation applied in advance. When digital compensation is made to perform the commutation in advance, the excitation current will also be applied in advance [2, 17]. This will produce the flux opposing that produced by the magnet pole and cause flux weakening, as indicated in Fig. 12. The flux weakening effect can raise the speed of the motor above

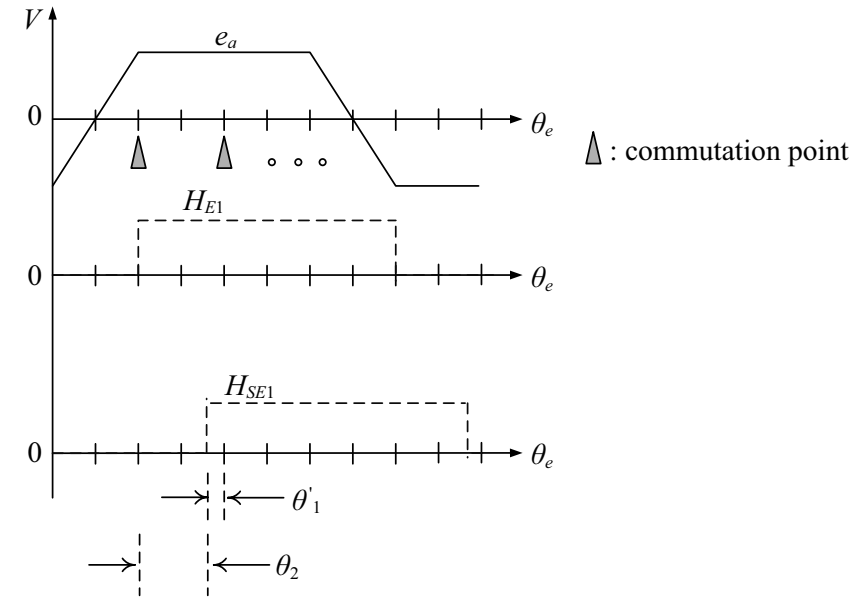

Fig. 13. Principle of phase advance control.

the rated speed. As shown in Fig. 13, controlling $\theta_{2}$ will control the commutation timing, as well as the current phase. Assuming that no phase lag occurs (i.e., $H_{E 1}$ appears at the commutation point, as shown in Fig. 13), to perform current phase advance control, a delay of $\theta_{2}<60^{\circ} \mathrm{E}$ can be used to allow a $\theta_{1}$, phase difference with the current leading the back EMF. It is noted that, as described above, another commutation table should be applied.

\section{EXPERIMENTAL STUDIES}

\section{General Sensorless Performance Tests}

It is important to investigate the performance under heavy load since this is a major drawback of sensorless techniques. Therefore, two experiments are arranged to test the performance: 1) speed regulation performance under a constant load, and 2) torque performance under a constant speed. The tests on the common BLDC commutation with Hall elements are also conducted and compared with the sensorless technique in terms of drive system efficiency. Moreover, the developed sensorless technique is further applied to a commercial thruster to verify the feasibility.

Loads are applied to the target motor (Fig. 7) via a dynamometer test bench (Fig. 14) after all the circuitry has been tested to be functionally correct. Figures 15 and 16 show the curves of efficiency against speed under constant loads $2 \mathrm{~N}-\mathrm{m}$ and $3 \mathrm{~N}-\mathrm{m}$ respectively. As can be seen, for $2 \mathrm{~N}-\mathrm{m}$, the efficiency of the proposed method almost matches the case equipped with Hall elements for a wide speed range. For 3 $\mathrm{N}-\mathrm{m}$, the efficiency of the proposed sensorless technique becomes slightly lower at some speeds. Figure 17 shows the performance comparison by varying loads up to $6 \mathrm{~N}-\mathrm{m}$ (rated torque) under the rated speed. As can be seen, for load greater than $3 \mathrm{~N}-\mathrm{m}$, the efficiency of the presented technique gradually decreases compared to the drive with Hall elements.

As shown in Fig. 18, Ch1 and $\mathrm{Ch} 2$ are respectively the terminal voltage and current of Phase A for the common BLDC 


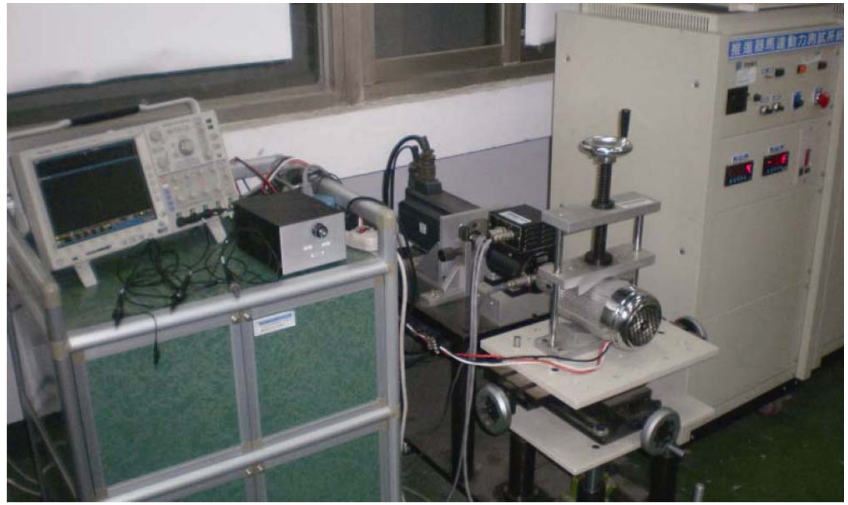

Fig. 14. The dynamometer test bench.

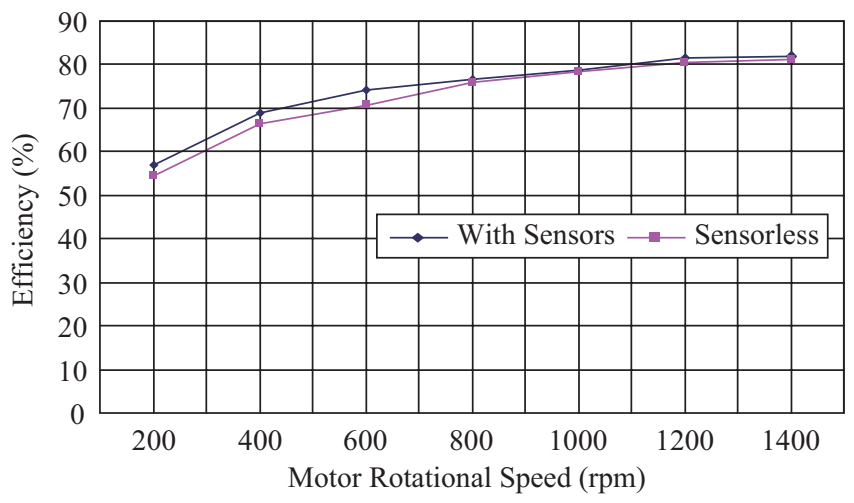

Fig. 15. Efficiency of varying speed under $2 \mathrm{~N}-\mathrm{m}$.

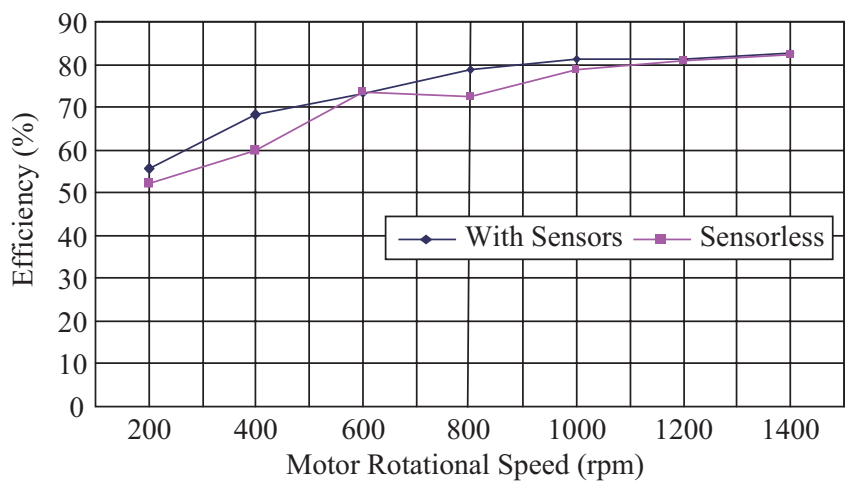

Fig. 16. Efficiency of varying speed under $3 \mathrm{~N}-\mathrm{m}$.

drive with Hall elements under a load of $2 \mathrm{~N}-\mathrm{m}$ at $1200 \mathrm{rpm}$. In contrast, Fig. 19 shows the same parameters obtained with the presented technique under the same load condition and speed. As can be seen and expected, the sensorless case requires a slightly larger (2.95\% greater) current in comparison with the case with Hall elements.

To sum up, Figs. 15 and 16 demonstrate that the proposed technique can operate the motor in the commutation mode to achieve a speed range from $200 \mathrm{rpm}$ to beyond the rated speed with load applied. The lowest speed at which the commuta-

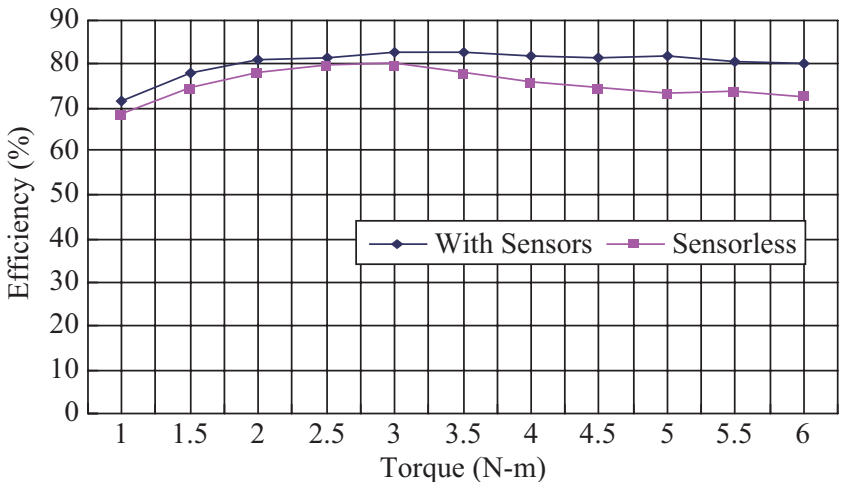

Fig. 17. Efficiency of varying torque under rated speed $(1200 \mathrm{rpm})$.

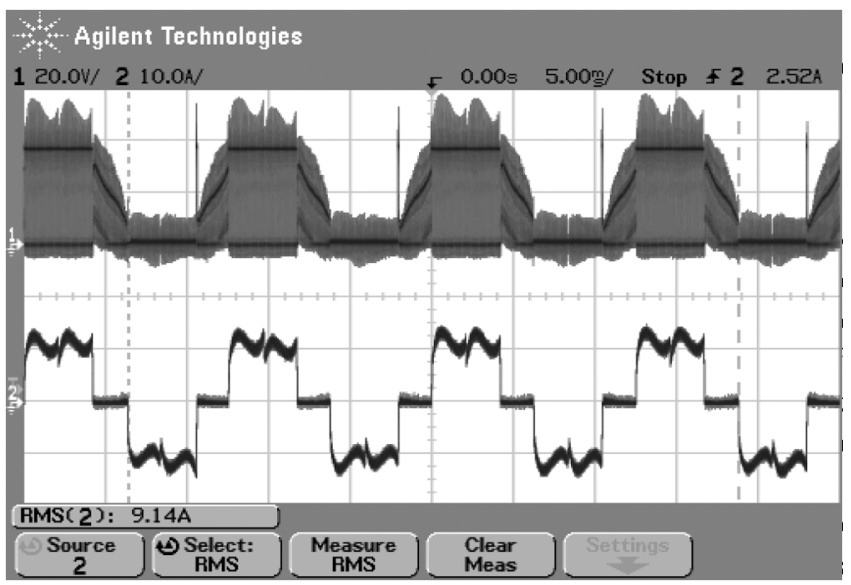

Fig. 18. Terminal voltage and phase current with sensors. (1: $20 \mathrm{~V} / \mathrm{div}, 2: 10 \mathrm{~A} / \mathrm{div}$; time: $5 \mathrm{~ms} / \mathrm{div}$ )

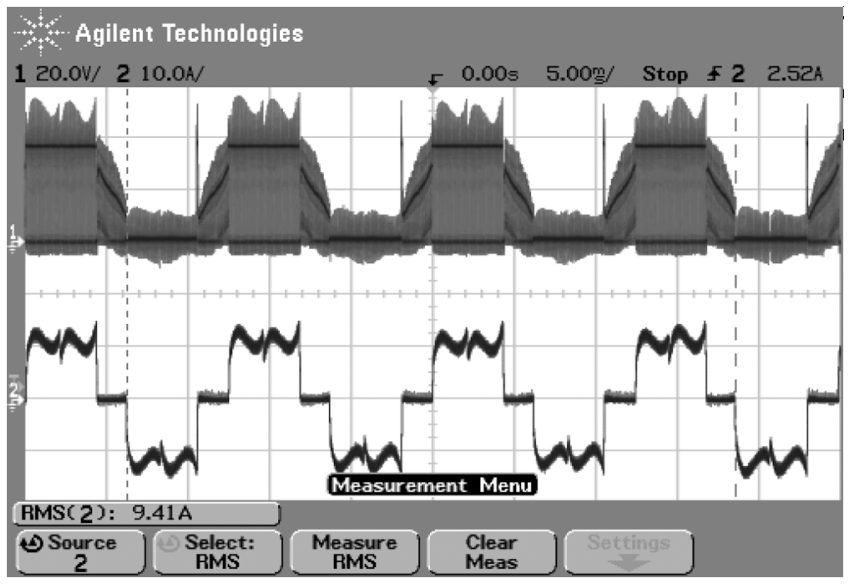

Fig. 19. Terminal voltage and phase current of sensorless. (1: $20 \mathrm{~V} / \mathrm{div}, 2: 10 \mathrm{~A} / \mathrm{div}$; time: $5 \mathrm{~ms} / \mathrm{div}$ )

tion using the estimated signals can be applied is $200 \mathrm{rpm}$. This implies that the synchronous mode is only required from 0 to $200 \mathrm{rpm}$. In addition, Fig. 17 also presents that the BLDC motor, with the developed sensorless technique, can be operated at the rated torque under the rated speed by a small effi- 


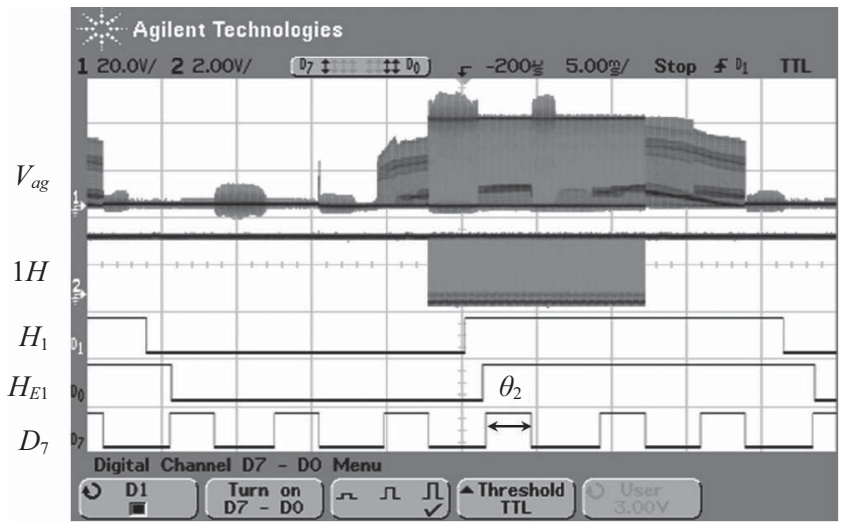

Fig. 20. Signals for phase advance control. (1: 20 V/div; 2: 2 V/div; D0, D1, D7: Digital; time: $5 \mathrm{~ms} /$ div)

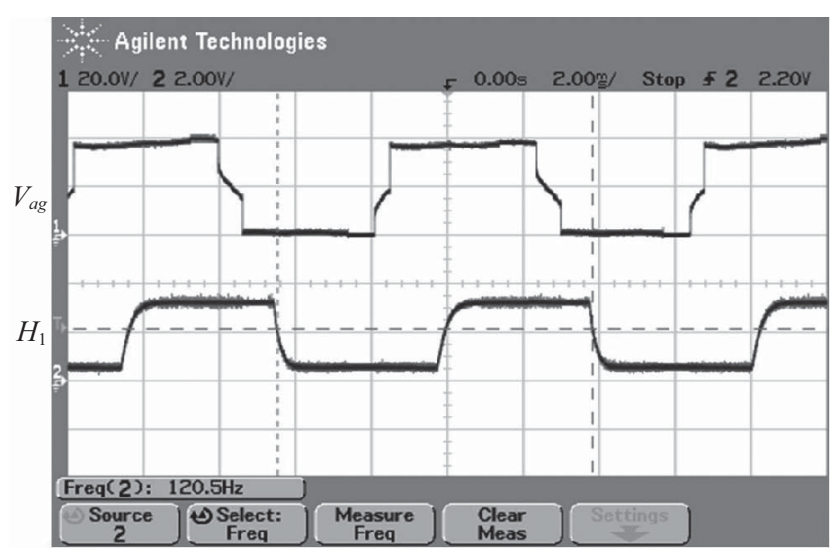

Fig. 21. Terminal voltages and estimated commutation signal for phase advance on no-load operation.

(1: $20 \mathrm{~V} / \mathrm{div}, 2: 2 \mathrm{~V} / \mathrm{div}$; time: $2 \mathrm{~ms} / \mathrm{div})$

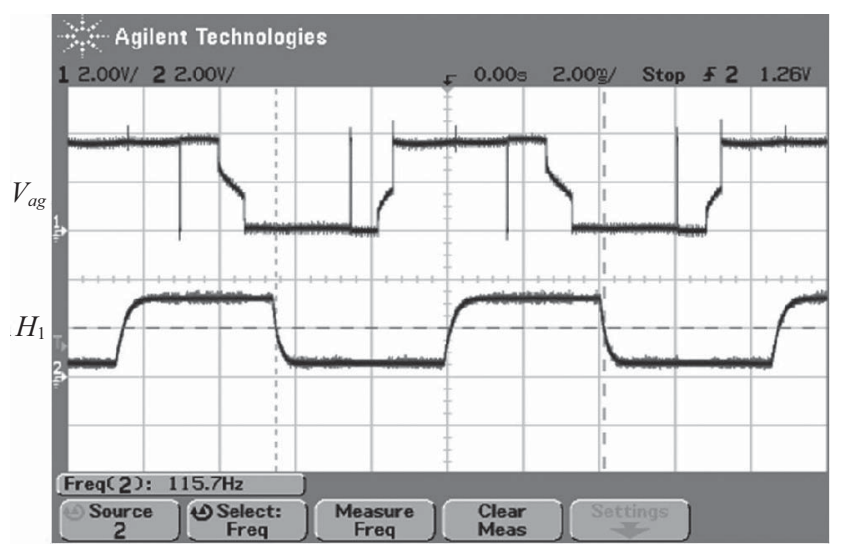

Fig. 22. Terminal voltages and estimated commutation signal for phase advance on $2 \mathrm{~N}-\mathrm{m}$ load operation.

(1: $20 \mathrm{~V} / \mathrm{div}, 2: 2 \mathrm{~V} / \mathrm{div}$; time: $2 \mathrm{~ms} / \mathrm{div}$ )

ciency drop. Therefore, this demonstrates the effectiveness of the presented technique that is capable of operating for a wide speed range under heavy load condition.

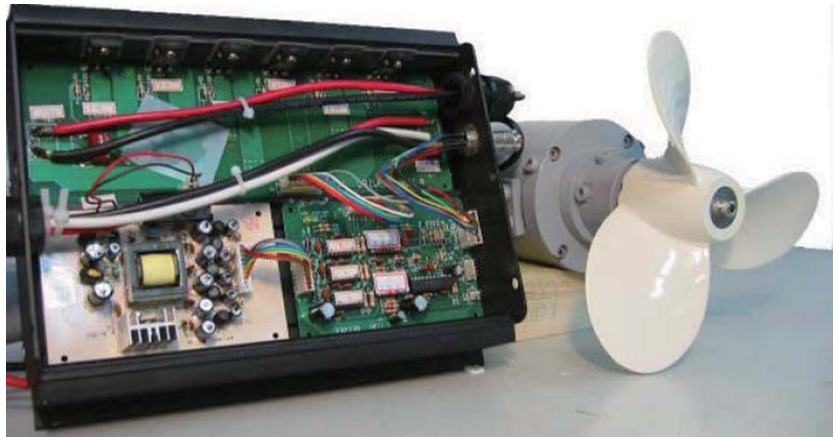

(a)

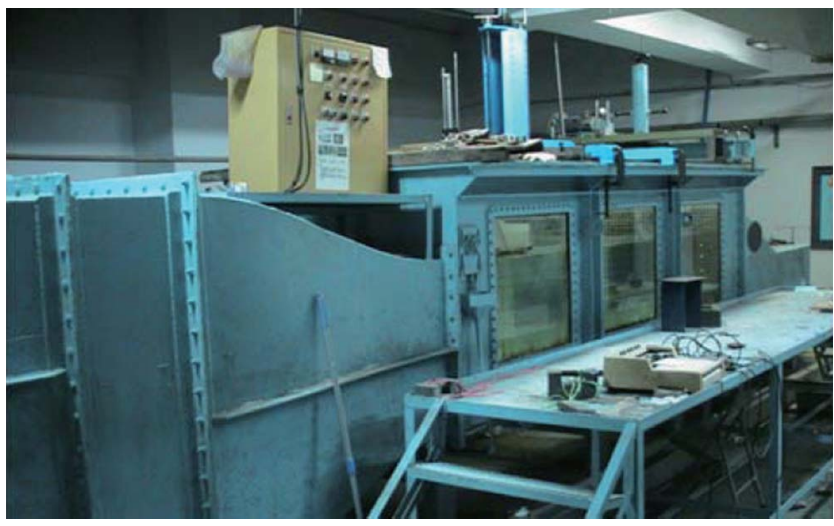

(b)

Fig. 23. The experimental setups: (a) the thruster and driver; (b) the circulation tank.

\section{Phase Advance Control}

For the phase advance control, the results are shown in Figs. 20-22. The definitions of the symbols in Fig. 20 are the same as in Fig. 11, and $\theta_{2}$ in Fig. 20 indicates the angle to delay so that the phase advance can be achieved. $\theta_{2}$ can be calculated according to the previous explanation. Figure 21 shows the speed $(1800 \mathrm{rpm}, 120 \mathrm{~Hz})$ the motor reaches by employing phase advance control under no load condition. This is higher than the original no load speed of the motor, i.e., 1650 rom.

For the case with $2 \mathrm{~N}-\mathrm{m}$ applied, as can be seen in Fig. 22, the speed achieved is $1740 \mathrm{rpm}$ with the phase advance control. This is also greater than the speed under the same load for the drive with Hall elements (1500 rpm). The above experiments have confirmed the effectiveness of the developed phase advance control.

\section{In-Water Thruster Test}

A thruster (Fig. 23(a)) direct driven by another motor is tested in water. This is a commercially available unit without details of the propeller characteristics and motor parameters. During the in-water experiments, the thruster shaft torque cannot be directly measured. Nevertheless, the performance of the developed sensorless technique can still be tested by measuring the input power, which is then compared with that of the drive with Hall elements. For the same propeller run- 


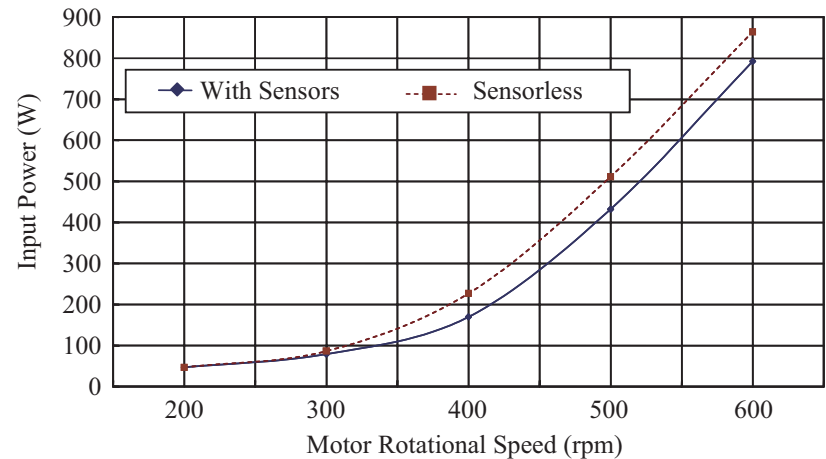

(a)

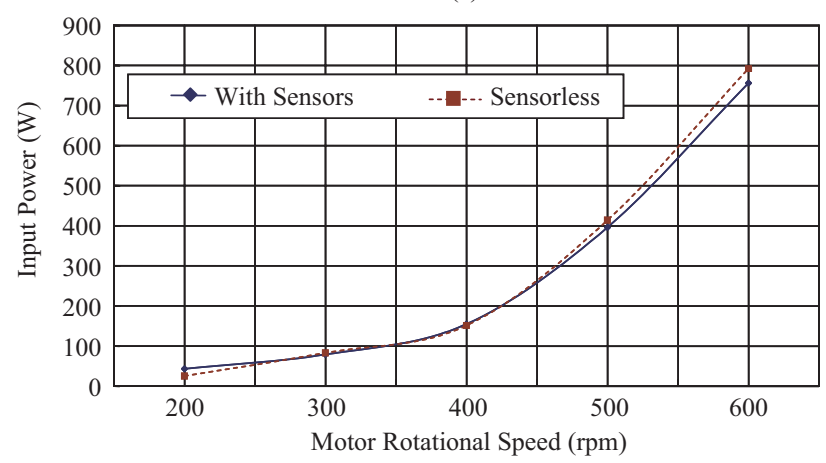

(b)

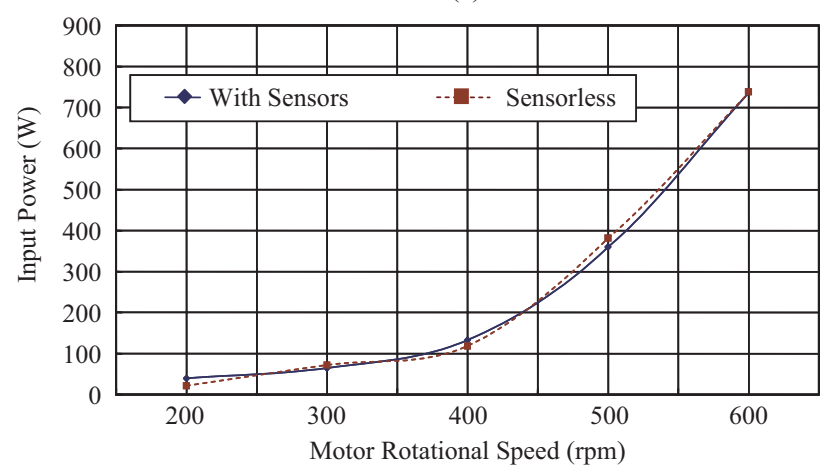

(c)

Fig. 24. In-water test results: (a) no flow speed, (b) $0.5 \mathrm{~m} / \mathrm{s}$ flow speed and (c) $0.77 \mathrm{~m} / \mathrm{s}$ flow speed.

ning at the same rotational speed and inlet water velocity, the input power to the same motor should ideally be the same, unless the driving technique is different. As shown in Fig. 23(b), the experiments are conducted in a circulation tank with adjustable flow speed. The result in Fig. 24(a) is the case with zero flow speed while that in Figs. 24(b) and 24(c) has flow speeds of $0.5 \mathrm{~m} / \mathrm{s}$ and $0.77 \mathrm{~m} / \mathrm{s}$ respectively. As can be see, the performance of the developed sensorless drive can match that with sensors in all the three conditions.

From Figs. 24(a) to 24(c), it can be further observed that, the higher the flow speed, the lower the torque required at the same rotational speed. This matches the pattern shown in Fig. 1 , and thus the correctness of the experimental results here is confirmed. It is noted that the phase advance technique is not applied in the in-water test.

\section{CONCLUSION}

This paper has developed a sensorless driving technique for BLDC motors and electric propulsors. This technique made use of a low-pass filter with two cut-off frequencies that can be regulated for various speed operations. The higher cut-off frequency was designed for high speed to reduce phase lag, and the lower one was used for start-up to reject the noise. From the experiments, with loads applied, the developed technique was capable of increasing the speed beyond the rated speed. The BLDC motor can be operated in the commutation mode from a $200 \mathrm{rpm}$ low speed using the estimated signals acquired by the developed circuits. For the entire speed range, the proposed technique demonstrated high efficiency even at high torque, high speed condition. Thus, the performance of the developed technique can match that of drives with Hall elements. The tests for the electric propulsors in water have also shown that the proposed method can have a decent efficiency and performance compared to that of Hall-element commutation.

\section{ACKNOWLEDGMENTS}

This research work was supported by the National Science Council, Taiwan ROC, under contract 95-2221-E-006-471 and 96-2622-E-006-029-CC3. The authors would like to thank Joseph Tech Co. for their help in experiments. Dr. Cheng-Hu Chen is also acknowledged for his advice during the research period.

\section{REFERENCES}

1. Batzel, T. D. and Lee, K.-Y., "Electric propulsion with sensorless permanent magnet synchronous motor: Model and approach," IEEE Transactions on Energy Conversion, Vol. 20, No. 4, pp. 818-825 (2005).

2. Becerra, R. C. and Ehsani, M., "High-speed torque control of brushless permanent magnet motors," Transactions on Industrial Applications, Vol. 35, No. 3, pp. 402-406 (1988).

3. Chen, C.-H. and Cheng, M.-Y., "A new sensorless control scheme for brushless DC motors without phase shift circuit," Proceedings of IEEE Power Electronics and Drive System Conference, Vol. 2, pp. 1084-1089 (2005).

4. Chen, C.-H. and Cheng, M.-Y., "Design of a multispeed winding for a brushless DC motor and its sensorless control," IEE Proceedings of Electric Power Applications, Vol. 153, No. 6, pp. 834-841 (2006).

5. Chen, C.-H., Tai, W.-C., and Cheng, M.-Y., "A cost effective sensorless control method for permanent magnet synchronous motors based on average terminal voltage," Proceedings of the International Power Electronics and Motion Control Conference, Shanghai (2006).

6. Chen, H.-C. and Liaw, C.-M., "Sensorless control via intelligent commutation tuning for brushless DC motor," IEE Proceedings: Electric Power Applications, Vol. 146, No. 6, pp. 678-684 (1999).

7. Damodharan, P. and Vasudevan, K., "Indirect back-EMF zero crossing detection for sensorless BLDC motor operation," Proceedings of IEEE Power Electronics and Drive System Conference, Vol. 2, pp. 1107-1111 (2005).

8. Hadler, J. B., Pien, P.-C., and Sheng, C.-P., Systematic Series of Tandem Propellers, Webb Institute of Naval Architecture, New York (1984).

9. Hsieh, M.-F., Chen, J.-H., Yeh, Y.-H., Lee, C.-L., Chen, P.-H., Hsu, Y.-C., and Chen, Y.-H., "Integrated design and realization of a hubless rim- 
driven thruster," Proceedings of the 33rd Annual Conference of the IEEE Industrial Electronics Society (IECON'07), Taipei, Taiwan (2007).

10. Hsieh, M.-F. and Hsu, Y.-S., "An investigation on influence of magnet arc shaping upon back electromotive force waveforms for design of permanent-magnet brushless motors," IEEE Transactions on Magnetics, Vol. 41, No. 10, pp. 3949-3951 (2005).

11. Hsieh, M.-F. and Hsu, Y.-C., "Characteristics regulation for manufacture of permanent-magnet motors using post-assembly magnetization," IEEE Transactions on Magnetics, Vol. 43, No. 6, pp. 2510-2512 (2007).

12. Iizuka, K., Uzuhashi, H., Kano, M., Endo, T., and Mohri, K., "Microcomputer control for sensorless brushless motor," IEEE Transactions on Industrial Applications, Vol. 21, No. 4, pp. 595-601 (1985).

13. Jiang, Q., Bi, C., and Huang, R., "A new phase-delay method to detect back EMF zero-crossing points for sensorless control of spindle motors," IEEE Transactions on Magnetics, Vol. 41, No. 7, pp. 2287-2594 (2005).

14. Moreira, J. C., "Indirect sensing for rotor flux position of permanen magnet AC motors operating in a wide speed range," Transactions on Industrial Applications, Vol. 32, No. 6, pp. 1394-1401 (1996).
15. Ogasawara, S. and Akagi, H., "An approach to position sensorless drive for brushless DC motor," Transactions on Industrial Applications, Vol. IA-27, No. 5, pp. 928-933 (1991).

16. Shao, J., Nolan, D., Teissier, M., and Swanson, D., "A novel microcontroller-based sensorless brushless DC (BLDC) motor drive for automotive fuel pumps," Transactions on Industrial Applications, Vol. 39, No. 6, pp. 1734-1740 (2003).

17. Shen, J.-X., Zhu, Z.-Q., and Howe, D., "Sensorless flux-weakening control of permanent magnet brushless machines using third-harmonic back-EMF," Transactions on Industrial Applications, Vol. 40, No. 6, pp. 1629-1636 (2004).

18. Snary, P., Bhangu, B., Bingham, C. M., Stone, D. A., and Schofield, N., "Matrix converters for sensorless control of PMSMs and other auxiliaries on deep-sea ROVs," IEE Proceedings: Electric Power Applications, Vol. 152, No. 2, pp. 382-392 (2005).

19. Su, G.-J. and McKeever, J. W., "Low-cost sensorless control of brushless DC motors with improved speed range," IEEE Transactions on Power Electronics, Vol. 19, No. 2, pp. 296-302 (2004). 